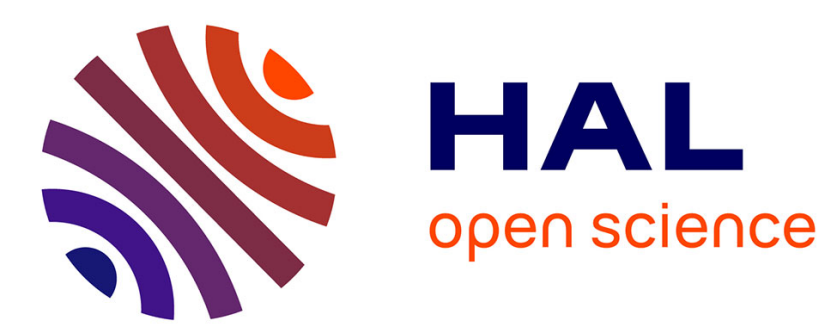

\title{
Influence of nitrogen impurities on the formation of active species in Ar-O plasmas
}

\author{
V. Guerra, K. Kutasi, P.A. Sá, M. Lino da Silva
}

\section{To cite this version:}

V. Guerra, K. Kutasi, P.A. Sá, M. Lino da Silva. Influence of nitrogen impurities on the formation of active species in Ar-O plasmas. European Physical Journal: Applied Physics, 2011, 56 (2), pp.24004. 10.1051/epjap/2011110194 . hal-00746213

\section{HAL Id: hal-00746213 \\ https://hal.science/hal-00746213}

Submitted on 28 Oct 2012

HAL is a multi-disciplinary open access archive for the deposit and dissemination of scientific research documents, whether they are published or not. The documents may come from teaching and research institutions in France or abroad, or from public or private research centers.
L'archive ouverte pluridisciplinaire HAL, est destinée au dépôt et à la diffusion de documents scientifiques de niveau recherche, publiés ou non, émanant des établissements d'enseignement et de recherche français ou étrangers, des laboratoires publics ou privés. 


\title{
Influence of nitrogen impurities on the formation of active
}

\section{species in $\mathrm{Ar}-\mathrm{O}_{2}$ plasmas}

\author{
Vasco Guerra $^{1,2}$, Kinga Kutasi ${ }^{3}$, Paulo A. Sá ${ }^{1,4}$, and M. Lino da Silva ${ }^{1}$ \\ 1 Instituto de Plasmas e Fusão Nuclear, Instituto Superior Técnico, 1049-001 Lisboa, Portugal \\ ${ }^{2}$ Departamento de Física, IST, Universidade Técnica de Lisboa, Portugal \\ 3 Research Institute for Solid State Physics and Optics, Hungarian Academy of Sciences, POB 49, H-1525 Budapest, Hungary \\ 4 Departamento de Engenharia Física, Faculdade de Engenharia da Universidade do Porto, 4200-465 Porto, Portugal
}

Received: date / Revised version: date

\begin{abstract}
A self-consistent kinetic model was developed in order to study the production of active species in $\mathrm{Ar}-\mathrm{O}_{2}$ surface-wave microwave plasmas with a relatively small $\mathrm{N}_{2}$ addition. It is shown that the Ar- $\mathrm{O}_{2}-$ $\mathrm{N}_{2}$ mixture produces efficiently the same active species as an $\mathrm{Ar}-\mathrm{O}_{2}$ discharge, including oxygen atoms, metastable $\mathrm{O}_{2}\left(a^{1} \Delta_{g}\right)$ molecules and the VUV emitting $\operatorname{Ar}(4 \mathrm{~s})$ states. Furthermore, active N-containing species are additionally produced, in particular N atoms and NO ground-state and excited molecules, which makes the ternary mixture very interesting for numerous plasma applications.
\end{abstract}

\section{Introduction}

Low-pressure $\mathrm{Ar}-\mathrm{O}_{2}$ surface-wave microwave discharges and their afterglows are very efficient sources of active species, such as $\mathrm{O}\left({ }^{3} \mathrm{P}\right)$ atoms, $\mathrm{O}_{2}\left(a^{1} \Delta_{g}\right)$ and $\mathrm{O}_{2}\left(b^{1} \Sigma_{g}^{+}\right)$ metastables, ozone, metastable $\operatorname{Ar}\left({ }^{3} \mathrm{P}_{2},{ }^{3} \mathrm{P}_{0}\right)$ and resonant $\operatorname{Ar}\left({ }^{3} \mathrm{P}_{1},{ }^{1} \mathrm{P}_{1}\right)$ argon atoms, as well as a variety of ions. They are thus interesting for several applications, for instance plasma sterilization [1-5], synthesis of nanowires $[6,7]$, wool treatment [8], different surface treatment processes [9-15], damaging of cancer cells [16,17] or the iodine- oxygen laser excitation [18-21]. We have recently conducted a thorough theoretical investigation on the formation of active species in these discharges $[22,23]$, discussing in detail their main creation and destruction mechanisms and the conditions where they can be efficiently produced. However, nitrogen impurities are often present in $\mathrm{Ar}, \mathrm{O}_{2}$ or Ar- $\mathrm{O}_{2}$ discharges, as confirmed by the frequent experimental detection of the emission of N-containing species. The purpose of this work is to address this issue, by extending our previous models to the case of $\mathrm{Ar}-\mathrm{O}_{2}-\mathrm{N}_{2}$ mixtures and by studying the influence of a small addition of 
nitrogen into an $\mathrm{Ar}-\mathrm{O}_{2}$ discharge. Our analysis is twofold.

On the one hand, we want to verify up to what point a small addition of nitrogen may affect the existing $\mathrm{Ar}-\mathrm{O}_{2}$ active species which are important for the various applications. On the other hand, we want to determine if the presence of nitrogen may lead to the significant production of other active species, namely $\mathrm{N}\left({ }^{4} \mathrm{~S}\right)$ atoms, $\mathrm{N}_{2}(\mathrm{~A})$ metastables and NO excited molecules, which may have a role in processing.

The system under analysis consists of a surface-wave discharge created by a microwave field at $f=2.45 \mathrm{GHz}$ in a $5 \mathrm{~mm}$ inner diameter cylindrical quartz tube at $p=4$ mbar. The working gas mixture is $10 \% \mathrm{O}_{2}-90 \% \mathrm{Ar}$, into which nitrogen is added. Therefore, the initial Ar to $\mathrm{O}_{2}$ ratio is always kept at 9:1, and the notation $\% \mathrm{~N}_{2}$ refers to the initial nitrogen concentration in the mixture. These operating conditions correspond to the ones used in $[24,11]$ in surface contamination cleaning and sterilization experiments. The delivered microwave power in the experiments from [11] was $100 \mathrm{~W}$.

The remaining of the paper is organized as follows. Section 2 shortly describes the kinetic model developed in this study. The results and their discussion are presented in section 3. Finally, the results are briefly summarized in section 4 .

\section{Theoretical model}

The structure of the model was described in detail in previous publications. Basically, the homogeneous electron Boltzmann equation is solved in the two-term expansion in spherical harmonics, coupled with a set of rate balance equations describing the creation and loss of the most important neutral and ionic species, including the molecular excited states $\mathrm{O}_{2}\left(a^{1} \Delta_{g}, b{ }^{1} \Sigma_{g}^{+}\right), \mathrm{N}_{2}\left(A^{3} \Sigma_{u}^{+}, B{ }^{3} \Pi_{g}\right.$, $\left.C^{3} \Pi_{u}, a^{\prime}{ }^{1} \Sigma_{u}^{-}, a^{1} \Pi_{g}, w^{1} \Delta_{u}\right)$ and $\operatorname{NO}(A, B)$, groundstate $\operatorname{Ar}\left({ }^{1} S_{0}\right), \mathrm{O}\left({ }^{3} P\right)$ and $\mathrm{N}\left({ }^{4} S\right)$ atoms, excited $\operatorname{Ar}\left({ }^{3} P_{2}\right.$, $\left.{ }^{3} P_{1},{ }^{3} P_{0},{ }^{1} P_{1}\right), \mathrm{O}\left({ }^{1} D\right)$ and $\mathrm{N}\left({ }^{2} D,{ }^{2} P\right)$ atoms, $\mathrm{NO}(X)$ and $\mathrm{O}_{3}$ molecules, the manifold of vibrational $\mathrm{N}_{2}\left(X^{1} \Sigma_{g}^{+}, \mathrm{v}\right)$ levels, and $\mathrm{Ar}^{+}, \mathrm{Ar}_{2}^{+}, \mathrm{O}^{+}, \mathrm{O}_{2}^{+}, \mathrm{N}_{2}^{+}, \mathrm{N}_{4}^{+}, \mathrm{NO}^{+}$and $\mathrm{O}^{-}$ ions. The full set of reactions considered in the $\mathrm{Ar}-\mathrm{O}_{2}$ system is detailed in $[22,23]$. Information related to the $\mathrm{N}_{2}-\mathrm{Ar}$ reactions can be found in $[25-27]$, to the $\mathrm{N}_{2}-\mathrm{O}_{2}$ kinetics in [28-30], and to the vibration kinetics and the calculation of the vibration levels in $[31,32]$. The system of equations is solved in stationary discharge conditions, considering an electron density corresponding to the critical density for surface-wave propagation, $n_{e}=3.74 \times 10^{11} \mathrm{~cm}^{-3}[22]$, describing approximately the conditions at the end of the plasma column. All the calculations in the discharge were performed assuming a gas temperature $T_{g}=500 \mathrm{~K}[33$, 23], but the sensitivity of the model to the value used for the gas temperature is briefly evaluated in the end of the next section. The concentrations obtained from the stationary model can then be used as initial values for the time relaxation in the afterglow, where the same system of rate balance equations is solved for the heavy-particles together with the continuity equation for the electron density, neglecting all electron impact excitation, dissociation and ionization processes. Notice, however, that electronion recombination is included in the system of rate balance 
equations in the post-discharge [23]. The gas temperature in the afterglow was assumed to be $T_{g}=300 \mathrm{~K}$. The time-dependent calculated profiles can be converted into spacial-dependent profiles by knowing the gas flow.

A relevant phenomenon can be the modification of the oxygen atomic wall recombination probability, $\gamma_{O}$, with the presence of small amounts of nitrogen. Indeed, a pronounced decrease of this recombination probability was found and discussed in [34-36]. A review on literature data and further discussion of this topic can be found in [37]. A correct treatment of this question involves the coupling of the present model to a system of equations describing the surface kinetics, such as the ones presented in $[36,38]$. However, the uncertainties surrounding the data of the elementary surface processes recommend the use of surface models only if accompanied by a comparison with a consistent set of measurements for the particular conditions under study. As such measurements are currently unavailable, the present results were obtained considering a constant value for $\gamma_{O}$, equal to $8 \times 10^{-3}$ [39]. A more detailed analysis of the modifications in $\gamma_{O}$ as a result of the presence of impurities, as well as the impact in the overall composition of the plasma, will be performed in future.

\section{Results and discussion}

Our models have been validated in previous publications by a systematic comparison with very complete sets of measurements in various operating conditions, both in pure gases and in $\mathrm{Ar}-\mathrm{N}_{2}$ and $\mathrm{N}_{2}-\mathrm{O}_{2}$ mixtures. The com-

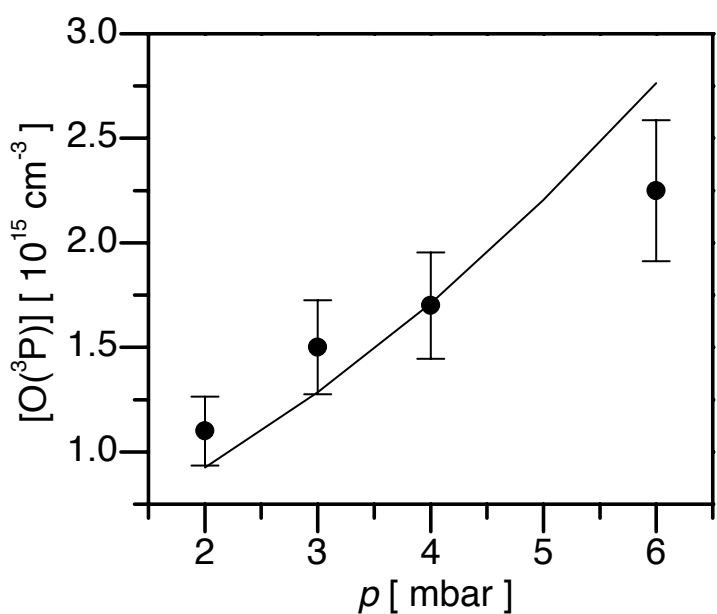

Fig. 1. $\mathrm{O}\left({ }^{3} P\right)$ concentration as a function of pressure: the full curves are the model results, the experimental points with error bars are the measurements reported in [11] for the afterglow. The delivered microwave power was $100 \mathrm{~W}$.

plete list of references would be too long to include here, so references [40-43] should merely be seen as supplementary examples. However, despite the importance of $\mathrm{Ar}-\mathrm{O}_{2}-\mathrm{N}_{2}$ surface-wave discharges and their afterglows for many applications, the experimental characterization of the active species for the conditions of this study is relatively poor.

A comparison of our calculations with most of the few available data for the $\mathrm{Ar}-\mathrm{O}_{2}$ mixture is presented in $[22$, 23]. An additional comparison between the model predictions and the experimental measurements is now shown in figure 1. The experimental points with error bars are taken from [11] and correspond to a position of $45 \mathrm{~cm}$ from the plasma gap. We estimate this corresponds to an afterglow time of about $2 \mathrm{~ms}$. Nevertheless, it must be noted that there are large uncertainties on the time-space conversion, mostly related to the determination of the plasma column 
end and the gas temperature, both values being modified with pressure and affecting the afterglow time corresponding to a certain position. Still, the agreement between the calculations and the measurements is remarkably good. As pointed out in [22], in discharges containing $90 \%$ argon, $\mathrm{O}\left({ }^{3} P\right)$ atoms are formed both by electron impact dissociation of $\mathrm{O}_{2}(X, a, b)$ molecules and dissociation in collisions with the $\operatorname{Ar}(4 \mathrm{~s})$ states,

$$
A r(4 s)+O_{2}(X) \rightarrow A r\left({ }^{1} S_{0}\right)+O\left({ }^{3} P\right)+O\left({ }^{3} P,{ }^{1} D\right)
$$

the two channels giving comparable contributions to the formation of atomic oxygen, whereas they are essentially destroyed by recombination at the wall. Anyhow, the behavior of the dissociation with pressure is in general rather complex and, together with a more accurate afterglow space-time conversion, will be investigated in detail in a future publication.

The influence of nitrogen addition into a $90 \% \mathrm{Ar}-10 \% \mathrm{O}_{2}$ discharge can be evaluated in figures 2-7. Figure 2 shows the concentration of the $\operatorname{Ar}(4 s)$ states as a function of the nitrogen concentration in the mixture. As it can be seen, the absolute concentration of excited argon atoms remains practically constant. Notice that the addition of nitrogen does not modify the kinetics of the $\operatorname{Ar}(4 s)$ states, whereas the sustaining reduced field slightly increases with the nitrogen concentration in the mixture as a result of the higher electron-impact cross sections in nitrogen. As a matter of fact, these higher cross sections lead to a more effective depopulation of the high-energy tail of the Electron Energy Distribution Function (EEDF), so that the

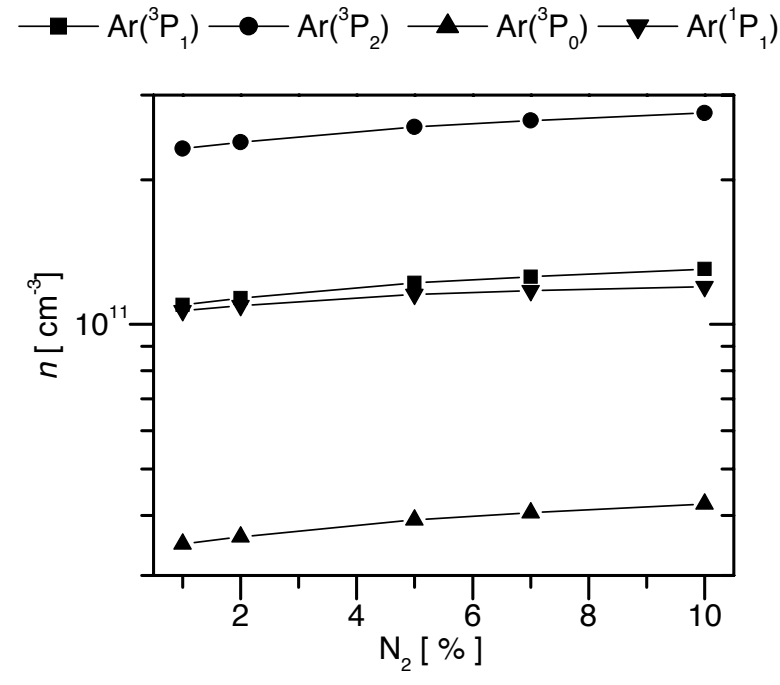

Fig. 2. Concentration of the $\operatorname{Ar}(4 s)$ states at the end of the plasma column as a function of the nitrogen content in the mixture, for $p=4$ mbar and an initial Ar to $\mathrm{O}_{2}$ ratio of 9:1.

reduced maintenance electric field has to increase in order to keep the same ionization degree $[28,22]$.

The effect of the nitrogen content on the oxygen species can be verified in figure 3 . As in the previous case, the introduction of up to $10 \%$ of nitrogen in the mixture has a negligible effect in the concentration of the active species. Most of the new reactions taking place contribute less than one percent to the formation or destruction of the oxygen species. Still, at $10 \% \mathrm{~N}_{2}$ in the mixture, dissociation of $\mathrm{O}_{2}$ by $\mathrm{N}_{2}(B)$ molecules,

$$
\mathrm{O}_{2}+\mathrm{N}_{2}(B) \rightarrow \mathrm{O}+\mathrm{O}+\mathrm{N}_{2}(X)
$$

gives $\sim 3 \%$ to the formation of atomic oxygen.

Figure 4 depicts the concentration of the nitrogen containing species, allowing to evaluate up to which point they can be used in plasma processing. Nitrogen atoms are particularly important, their population increasing more 


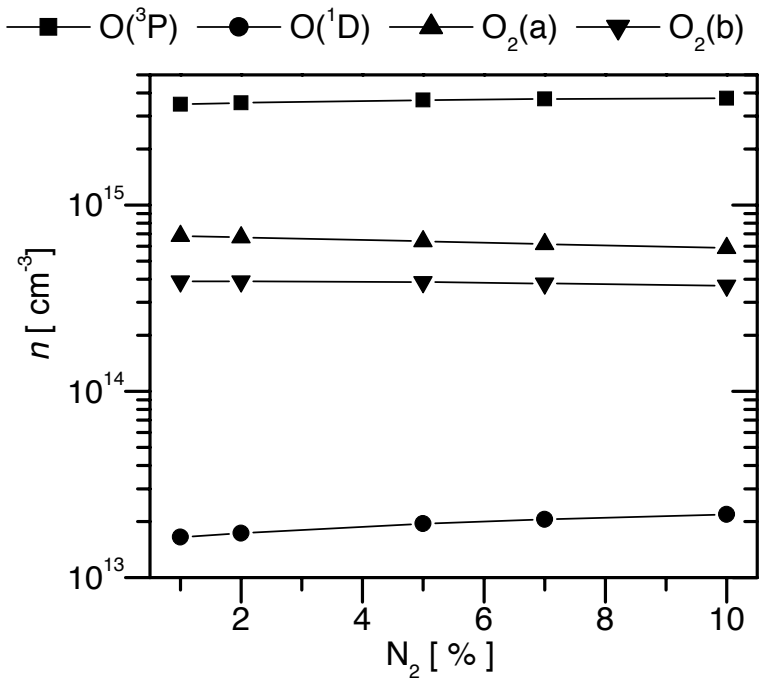

Fig. 3. Concentration of the oxygen species at the end of the plasma column as a function of the nitrogen content in the mixture, for $p=4$ mbar and an initial Ar to $\mathrm{O}_{2}$ ratio of 9:1.

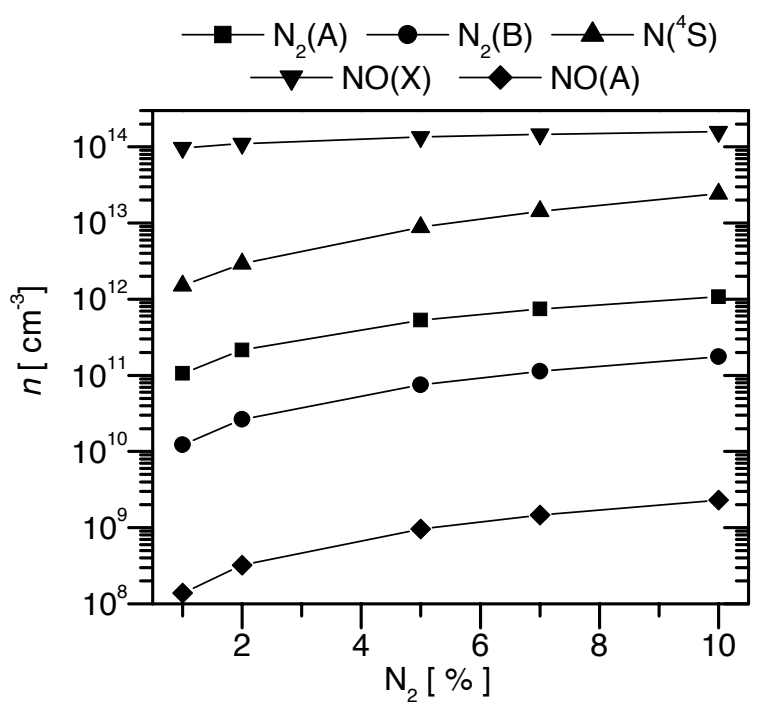

Fig. 4. Concentration of N-containing species at the end of the plasma column as a function of the nitrogen content in the mixture, for $p=4$ mbar and an initial Ar to $\mathrm{O}_{2}$ ratio of 9:1. than one order of magnitude when the nitrogen fraction raises from 1 to $10 \%$. The contribution of different processes to the formation of atomic nitrogen is represented in figure 5. At low $\mathrm{N}_{2}$ percentages, nitrogen atoms are mainly formed by electron impact dissociation, charge transfer from $\mathrm{N}_{2}^{+}$to $\mathrm{NO}^{+}$

$$
N_{2}^{+}+O\left({ }^{3} \mathrm{P}\right) \rightarrow N O^{+}+N\left({ }^{4} S\right)
$$

and total quenching (volume quenching by heavy-particles and electrons and surface quenching) of the metastable atomic state $\mathrm{N}\left({ }^{2} D\right)$. At this low concentrations of $\mathrm{N}_{2}$, electron-ion recombination

$$
e+N O^{+} \rightarrow N+O
$$

with a rate of the order of $2 \times 10^{-8} \mathrm{~cm}^{3} / \mathrm{s}$ for an electron temperature $\sim 1 \mathrm{eV}$, gives also a non-negligible contribution close to $10 \%$; however, its importance quickly decreases with $\mathrm{N}_{2}$ addition. At $10 \% \mathrm{~N}_{2}$ in the mixture, the dominant $\mathrm{N}\left({ }^{4} S\right)$ creation mechanism becomes the reaction of NO production

$$
N_{2}(X, v \geq 13)+O\left({ }^{3} P\right) \rightarrow N\left({ }^{4} S\right)+N O(X) .
$$

The strong increase of the importance of this process is the most striking feature revealed by figure 5 . Other important contributions come from electron impact dissociation and the aforementioned charge transfer process.

Another relevant species is NO. Its formation channels are also modified when the $\mathrm{N}_{2}$ content increases, as it can be seen in figure 6 . Thus, for low $\mathrm{N}_{2}$ concentrations it is essentially created by $\mathrm{NO}^{+}$neutralization at the wall and 


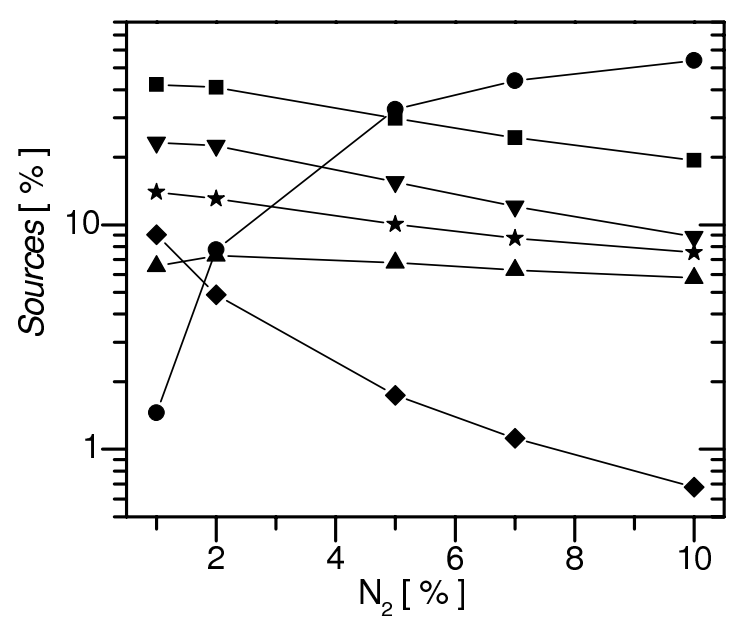

Fig. 5. Contribution of different mechanisms to the formation of $\mathrm{N}$ atoms, for $p=4$ mbar and an initial $\mathrm{Ar}$ to $\mathrm{O}_{2}$ ratio of 9:1: (匹) electron impact dissociation; $(\bullet) N_{2}(X, v \geq 13)+$ $O\left({ }^{3} P\right) \rightarrow N\left({ }^{4} S\right)+N O(X) ;(\boldsymbol{\Delta}) N_{2}\left(a^{\prime}\right)+N O \rightarrow N+O$ $\mathrm{N}_{2}^{+}+\mathrm{O}\left({ }^{3} \mathrm{P}\right) \rightarrow \mathrm{NO}^{+}+\mathrm{N}\left({ }^{4} \mathrm{~S}\right) ;(\diamond) e+N O^{+} \rightarrow \mathrm{N}+\mathrm{O} ;(\star)$ wall and volume quenching of $\mathrm{N}\left({ }^{2} D\right)$ atoms.

by the formation reaction involving $\mathrm{N}_{2}(A)$ molecules

$$
N_{2}(A)+O\left({ }^{3} P\right) \rightarrow N O(X)+N\left({ }^{2} D\right) .
$$

In contrast, at higher $\mathrm{N}_{2}$ fractions it is dominantly formed by the reaction involving vibrationally excited nitrogen molecules (5), the other two mechanisms just referred to giving as well non-negligible contributions. Further discussion on the competition between processes (5) and (6) can be found in $[44,45]$. The raise in importance of reaction (5) with the nitrogen content previously noted in figure (5) is clearly visible. It is a consequence of the strong enhancement of the fraction of vibrationally excited ground-state $\mathrm{N}_{2}(X, v)$ nitrogen molecules in levels $v \geq 13$, which increases almost two orders of magnitude, from $4.7 \times 10^{-4}$ to $3.5 \times 10^{-2}$, when the nitrogen percentage in the mixture goes from 1 to $10 \%$.

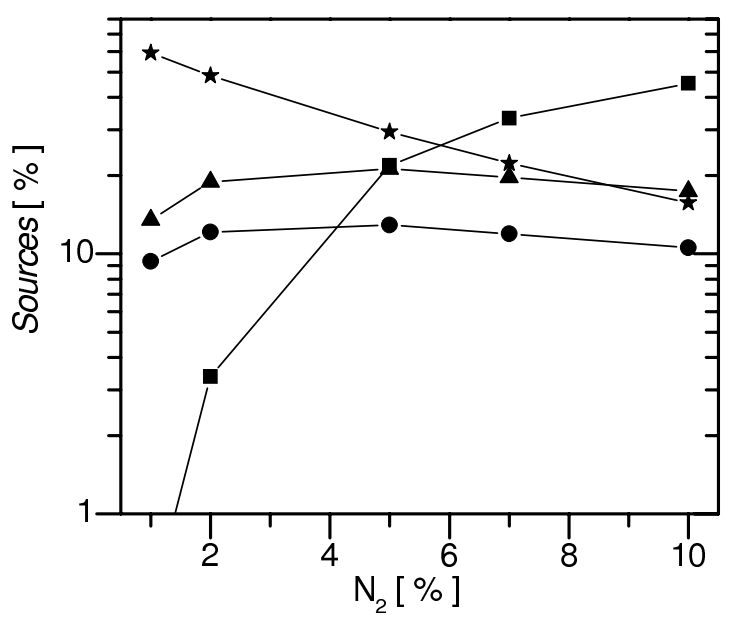

Fig. 6. Contribution of different mechanisms to the formation of NO molecules, for $p=4$ mbar and an initial Ar to $\mathrm{O}_{2}$ ratio of 9:1: (घ) $N_{2}(X, v \geq 13)+O\left({ }^{3} P\right) \rightarrow N\left({ }^{4} S\right)+N O(X)$;

$N\left({ }^{2} D\right)+O_{2} \rightarrow N O+N\left({ }^{4} S\right) ;(\mathbf{\Lambda}) N_{2}(A)+O\left({ }^{3} P\right) \rightarrow N O(X)+$ $N\left({ }^{2} D\right) ;(\star)$ wall neutralization of $\mathrm{NO}^{+}$ions.

It is also worth noting that UV emitting $\mathrm{NO}(A)$ molecules reach densities of the order of $10^{9} \mathrm{~cm}^{-3}$. Such population already provides a reasonable emission intensity, of special interest in biomedical applications and surface treatments. The kinetics of $\mathrm{NO}(A)$ is relatively simple, as this state is produced by the collisional energy transfer

$$
N_{2}(A)+N O(X) \rightarrow N_{2}(X, v=0)+N O(A)
$$

being destroyed by radiative decay and, in a smaller extent, by quenching with $\mathrm{O}_{2}$ molecules.

Figure 7 exhibits the ionic composition of the mixture. As it could be concluded from the discussion of the previous results, $\mathrm{NO}^{+}$quickly becomes the dominant ion, therefore playing a relevant role in the kinetics of several species. This is fundamentally a consequence of the very efficient charge transfer from $\mathrm{O}_{2}^{+}$and $\mathrm{N}_{2}^{+}$ions into $\mathrm{NO}^{+}$ $[46]$. 


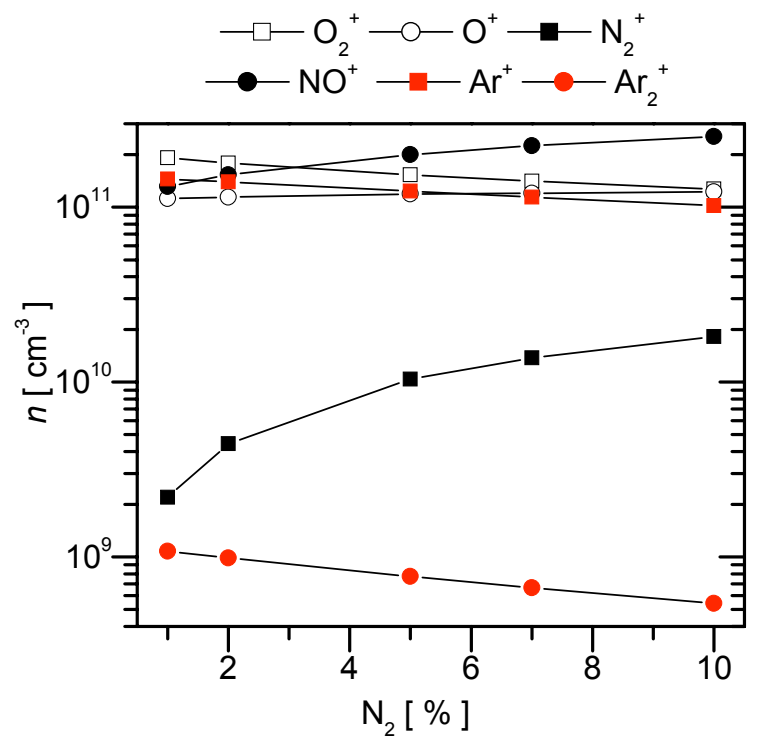

Fig. 7. Ionic populations at the end of the plasma column as a function of the nitrogen content in the mixture, for $p=4$ mbar and an initial Ar to $\mathrm{O}_{2}$ ratio of 9:1.

As the calculations have been made at constant gas temperature, $T_{g}=500 \mathrm{~K}$, it is important to estimate the influence of the gas temperature on the calculations. To this purpose, we have made the calculations using $T_{g}=700 \mathrm{~K}$, for the cases of $1 \%$ and $5 \% \mathrm{~N}_{2}$ in the mixture. The profiles of the different species are not modified, and the changes in the concentrations are rather small. For instance, for $1 \% \mathrm{~N}_{2}$ in the mixture the relative concentration of atomic nitrogen (oxygen) is changed from $2.6 \times 10^{-5}\left(6.0 \times 10^{-2}\right)$ to $3.1 \times 10^{-5}\left(5.5 \times 10^{-2}\right)$ when the gas temperature increases from $500 \mathrm{~K}$ to $700 \mathrm{~K}$, respectively, while it goes from $1.4 \times 10^{-4}\left(6.3 \times 10^{-2}\right)$ to $1.7 \times 10^{-4}\left(5.9 \times 10^{-2}\right)$ in the $5 \% \mathrm{~N}_{2}$ mixture.

\section{Conclusion}

In this work we have extended our previous models [22,23] to study the influence of nitrogen addition in $\mathrm{Ar}-\mathrm{O}_{2}$ discharges. The conditions of this investigation were the same as in the experiments from $[24,11]$, namely a microwave surface-wave discharge at $p=4$ mbar, with field frequency $f=2.45 \mathrm{GHz}$ and nitrogen introduction into a $90 \% \mathrm{Ar}-$ $10 \% \mathrm{O}_{2}$ mixture. It was shown that the concentration of argon and oxygen active species is not significantly modified by the introduction of up to $10 \% \mathrm{~N}_{2}$ in the mixture. Moreover, other species with potential interest in technological applications, such as $\mathrm{NO}(X, A, B)$ molecules, $\mathrm{N}\left({ }^{4} S\right)$ atoms and $\mathrm{NO}^{+}$ions, are additionally produced. Therefore, the ternary mixture $\mathrm{Ar}-\mathrm{O}_{2}-\mathrm{N}_{2}$ can indeed be advantageously used in several plasma processes, as suggested in [47-49] and pointed out in $[22,23]$.

Future work shall concentrate in finding the optimal conditions for the production of specific species required for a particular application and in investigating their timeevolution and survival time in the afterglow. The role of surface processes in the formation of molecules is also a pressing topic to be addressed $[36,50]$.

\section{Acknowledgement}

The work has been supported by the Portuguese Fundação para a Ciência e Tecnologia (FCT) funds to Instituto de Plasmas e Fusão Nuclear - Laboratório Associado and by the Janos Bolyai Research Scholarship of the Hungarian Academy of Sciences. 


\section{References}

1. Moreau S, Moisan M, Tabrizian M, Barbeau J, Pelletier J, Ricard A, and Yahia L 2000 J. Appl. Phys. 88 1166-1174

2. Nagatsu M, Terashita F, Nonaka H, Xu L, Nagata T and Koide Y 2005 Appl. Phys. Lett. 86211502

3. Rossi F, Kylián O and Hasiwa M 2006 Plasma Process. Polym. 3 431-442

4. Raballand V, Benedikt J, Wunderlich J and von Keudell A 2008 J. Phys. D: Appl. Phys. 41115207

5. Vratnica Z, Vujošević D, Cvelbar U and Mozetič M 2008 IEEE Trans. Plasma Sci. 36 1300-1301

6. Mozetič M, Cvelbar U, Sunkara M and Vaddiraju S 2005 Adv. Mater. 17 2138-2142

7. Cvelbar U, Ostrikov K and Mozetič M 2008 Nanotechnology 19405605

8. Canal C, Gaboriau F, Ricard A, Mozetic M, Cvelbar U and Drenik A 2007 Plasma Chem. Plasma Process. 27 404-413

9. Belmonte T, Czerwiec T, Gavillet J and Michel H 1997 Surface Coat. Technol. 97 642-648

10. Puač N, Petrović Z, Radetić M and Djordjević A 2005 Mater. Sci. Forum 494 291-296

11. Mafra M, Belmonte T, Poncin-Epaillard F, Maliska A and Cvelbar U 2009 Plasma Process. Polym. 6 S198-S203

12. Klanjšek-Gunde M, Kunaver M, Hrovat A and Cvelbar U 2005 Prog. Org. Coat. 54 113-119

13. Kitajima T, Nakano T and Makabe T 2006 Appl. Phys. Lett. 88091501

14. Mozetic M, Zalar A, Cvelbar U and Babic D 2004 Surf. Interface Anal. 36 986-988

15. Vesel A, Drenik A, Mozetic M, Zalar A, Balat-Pichelin M and Bele M 2007 Vacuum 82 228-231
16. Parker J G 1984 John Hopkins APL Technical Digest 5 $48-50$

17. Niedre M J, Yu C S, Patterson M S and Wilson B C 2005 British J. Cancer 92 298-304

18. Ionin A A, Kochetov I V, Napartovich A P and Yuryshev N N 2007 J. Phys. D: Appl. Phys. 40 R25-R61

19. Woodard B S, Zimmerman J W, Benavides G F, Carroll D L, Verdeyen J T, Palla A D, Field T H, Solomon W C, Lee S, Rawlins W T and Davis S J 2010 J. Phys. D: Appl. Phys. 43025208

20. Hicks A, Bruzzese J R and Adamovich I V 2010 J. Phys. D: Appl. Phys. 43025206

21. Guerra V, Kutasi K and Sá P A 2010 Appl. Phys. Lett. 96 071503

22. Kutasi K, Guerra V and Sá P 2010 J. Phys. D: Appl. Phys. 43175201

23. Kutasi K, Guerra V and Sá P A 2011 Plasma Sources Sci. Technol. 20035006

24. Ricard A and Monna V 2002 Plasma Sources Sci. Technol. 11 A150-A153

25. Sá P A and Loureiro J 1997 J. Phys. D: Appl. Phys. 30 $2320-2330$

26. Henriques J, Tatarova E, VGuerra and Ferreira C M 2002 J. Appl. Phys. 91 5622-5631

27. Henriques J, Tatarova E, Dias F M and Ferreira C M 2002 J. Appl. Phys. 91 5632-5639

28. Guerra V and Loureiro J 1997 Plasma Sources Sci. Technol. $6373-385$

29. Pintassilgo C D, Loureiro J and Guerra V 2005 J. Phys. D: Appl. Phys. $\mathbf{3 8} 417$

30. Kutasi K, Saoudi B, Pintassilgo C D, Loureiro J and Moisan M 2008 Plasma Process. Polym. 5 840-852 
31. Loureiro J and Ferreira C M 1986 J. Phys. D: Appl. Phys. $1917-35$

32. Lino da Silva M, Guerra V, Loureiro J and Sá P A 2008 Chem. Phys. $\mathbf{3 4 8} 187$

33. Tatarova E, Dias F M, Ferreira C M and Ricard A 1999 J. Appl. Phys. 85 49-62

34. Dilecce G and Benedictis S D 1999 Plasma Sources Sci. Technol. 8 266-278

35. Gordiets B F, Ferreira C M, Nahorny J, Pagnon D, Touzeau M and Vialle M 1996 J. Phys. D: Appl. Phys. 29 1021-1031

36. Gordiets B F and Ferreira C M 1998 AIAA Journal 36 $1643-1651$

37. Kutasi K and Loureiro J 2007 J. Phys. D: Appl. Phys. 40 $5612-5623$

38. Guerra V 2007 IEEE Trans. Plasma Sci. 35 1397-1412

39. Macko P, Veis P and Cernogora G 2004 Plasma Sources Sci. Technol. 13 251-262

40. Henriques J, Tatarova E, Dias F M and Ferreira C M 2001 J. Appl. Phys. 90 4921-4928

41. Pinheiro M J, Gousset G, Granier A and Ferreira C M 1998 Plasma Sources Sci. Technol. 7 524-536

42. Guerra V, Tatarova E, Dias F M and Ferreira C M 2002 J. Appl. Phys. 91 2648-2661

43. Guerra V, Sá P A and Loureiro J 2004 Eur. Phys. J. Appl. Phys. 28 125-152

44. Pintassilgo C D, Guaitella O and Rousseau A 2009 Plasma Sources Sci. Technol. 18025005

45. Welzel S, Guaitella O, Lazzaroni C, Pintassilgo C D, Rousseau A and Röpcke J 2011 Plasma Sources Sci. Technol. 20015020
46. Guerra V and Loureiro J 1999 Plasma Sources Sci. Technol. $6373-385$

47. Stapelmann K, Kylián O, Denis B and Rossi F 2008 J. Phys. D: Appl. Phys. 41192005

48. Kylián O and Rossi F 2009 J. Phys. D: Appl. Phys. 42 085207

49. Bernardelli E A, Ricard A and Belmonte T 2011 Plasma Sources Sci. Technol. 20025012

50. Guaitella O, Hübner M, Welzel S, Marinov D, Röpcke J and Rousseau A 2010 Plasma Sources Sci. Technol. 19 45026 